\title{
DE TOE BADJENG EN DE LEGENDE OMTRENT HUN OORSPRONG.
}

DOOR

\author{
J. TIDEMAN.
}

Controleur Binnenlandseh Bestuur.

De laatste expeditie op Zuid-Celebes heeft onder meer ten gevolge gehad de splitsing van het voormalige zelf besturende landschap Gowa in meerdere deelen, die alle voortaan een eigen inlandsch zelf bestuur verkregen, hetwelk echter zijne functiën onder de leiding van een Europeeschen Bestuursambtenaar uitoefent. Werd voor dat gedeelte, dat thans West-Gowa genoemd wordt, eerst een Assistent-Resident, doch al spoedig daarua een Controleur bij het Binnenlandsch-Bestuur in dienst gesteld, de overige gedeelten werden gebracht onder het toezicht van Bestuursambtenaren uit het direct bestuurd Gouvernementsgebied in de an Gowa grenzende streken. Zoo kwam het in de westelijke laagvlakte van Zuid-Celebes, bezuiden de rivier van Gowa of Djeneberang gelegen gedeelte - thans Zuid-Gowa genoemd - ouder bestuurstoezicht van den Controleur van Takalar.

Met uitzondering van zeer enkele Chineezen en slechts weinige tientallen Boegineezen, die zich daar metterwoon vestigden, bestaat de bevolking van Zuid-Gowa uitsluitend uit Makassaren. Onder dezen zijn er nu sommigen, die zich met zekeren trots Toe Badjeng 1 d. i. lieden van Badjeng noemen. Badjeng was eertijds een rijkje, gelegeu in de omgeving van de op ongeveer 5 paleu benoorden de afdeelingshoofdplaats Takalar liggende kampong Ballo, thans komt

1 Toe is een samentrekking van tâoe = mensch, en komt in dien vorm alleen in samenstellingen voor. Zoo beteekent Toemanoeroeng de (uit den Hemel) neergedaalde, zoo is de naam van de onderafdeeling Toerateialanden afgeleid van Toerate en dit weer van toe en irate, welk laatste woord boven en in dit verband 't zuiden beteekent. Aan den Westkant van Zuid-Celebes zegt men nâoeng (dalen) voor noordwaarts en nâi (stijgen) voor zuidwaarts gaan.

Toe Badjeng beteekent dus lieden van Badjeng of zooals men zou kunnen zeggen Badjengers. 
daar nog een gehucht van dien naam voor. Om tegenwoordig nog te spreken van het volk van Badjeng, zooals in sommige officieele stukken in het archief te Makassar wordt gedaan, zou tot de onjuiste gevolgtrekking aanleiding geven, dat Badjeng thans nog een bestuurseenheid vormt, te meer daar in diezelfde officiëele bescheiden van het district Badjeng gesproken wordt. Dit is beslist onjuist, want de Toe Badjeng hebben zich als het ware onder de overige Makassaren opgelost.

Zooals Prof. Dr. G. A. Wilken in zijne verhandeling over de verwantschap, het huwelijks- en erfrecht bij de volken van het Maleische ras releveert, is bij de alleroudste staten het denkbeeld der volkseenheid minder gelegen in het gemeenschappelijk bewonen van een land, dan wel in het begrip van gemeenschappelijke afstamming, daar oorspronkelijk bij den mensch geene andere voorstelling van het matschappelijk verband mogelijk was dan onder den vorm van een familieverband. "De stamverdeeling in zuiveren vorm", zegt Wilken, "is slechts mogelijk waar nomadeuleven bestaat; de volkeren van den Indischen Archipel zijn dat tijdperk te boven en bevinden zich in een overgangstoestand, waarbij naast de stamverdeeling de territoriale indeeling bestaat en deze beide op eigenaardige wijze met elkander verbonden zijn". In het bovengenoemde, thaus onder Takalar ressorteerende zelf besturende landschap Zuid-Gowa springt dit treffend in 't oog. De bestuursindeeling, zooals die in Gowa bestond, was zoowel een territoriale, als op stamverdeeling gebaseerd; doch dit laatste sprak zich nog zóó krachtig uit, dat lieden, die naar elders verhuisden, feitelijk nog onderhoorigen bleven van hun vroeger hoofd. Hierin ligt ook de verklaring van het ontstaan der vele soms ver van het oorspronkelijk gebied verwijderde enclaves, die de verschillende in Gowa macht gehad hebbende Karaengs tot huu gebied rekendeu.

De bestande bestuursindeeling in Gowa kon dan ook, toen het Gouveruement daar meer direct zijn invloed deed gelden, onmogelijk in haar geheel in staud gehouden worden, zonder dat de goede gang van zaken daardoor in hooge mate belemmerd zou worden. Wil men een voorbeeld, zoo beschouwe men het gebied van Bontoala. Dit is niet één afgerond geheel, doch wordt gevormd door meerdere overal in Gowa verspreide gedeelten, waarvan er alleen vijf in Zuid-Gowa, alle van elkaar gescheiden, voorkomen. Zelfs heeft een dier gedeelten, n.l. het gebied van den Anronggoeroe van Montjombalang wederom een enclave, een onder-euclave zou men kunnen $7^{\circ}$ Volgr. VI. 
zeggen, op eenige palen zuidwaarts van het eigen gebied gelegen! Tot op den tijd der laatste expeditie was Bontoala het gebied van Karaeng Mangeppe, den Hoofdvorst van Wadjo en had dus de vorst van Gowa aldaar in geenendeele de positie, die hij als zoodanig in de andere streken van zijn land innam. ${ }^{1}$

De Toe Badjeng nu verkeerden in een nog ander geval. Aan den eenen kant trad bij hen het stamverband veel sterker op den voorgrond, terwijl zij aan den anderen kant geen bestuurseenheid vormden, doch zich, als we reeds boven zagen, onder de overige bevolking van Gowa hebben gemengd. Echter zijn er nog vier kampongs, waar uitsluitend Toe Badjeng wonen en wel te Limboeng, Ballo, Koettoeloe (Mataällo) en Pamase. Naar het schijnt zijn de drie eerstgenoemde plaatsen eigenlijke vestigingen der Toe Badjeng in Gowa en dateert die te Pamase van lateren datum. De titel van de hoofden dier kampongs is Batang banowa (batang = stam, steel en banowa $=$ krisscheede). Omtrent den oorsprong dier benaming zeggen de Toe Badjeng zelven, dat eeus op een keer, toen huune hoofden, te dier tijde nog Glarrang genoemd, voor den vorst van Gowa verschenen, het lemmet van de kris van een hunner, den Glarrang van Badjeng (Limboeng), gestolen werd, welk lemmet niet werd teruggevonden, waarop de vorst toen tot hem zeide, "keer maar naar uw land terug, doch nu alleen met de scheede van uwen kris". Eene andere lezing zegt, dat de Glarrangs eertijds bij hunne bezoeken aan Gowa's vorst verplicht werden - vermoedelijk om hen te vernederen - om de messen hunner krissen onder aan de trap der vorstelijke woning te deponeeren en zij alleen met de scheede in tegenwoordigheid des vorsten mochteu verschijuen. Volgens de legende zou de vorst van Gowa wel eenige reden hebben, voorzichtigheid te betrachten tegenover een gewapenden Toe Badjeng en vooral een hoofd, want niet ua eerlijken en open strijd werden de Toe Badjeng gedwongen Gowa te "volgen", zooals de Makassaar

${ }^{1}$ Hier vergist schrijver zich. Karaeng Mangeppe, oom van den laatsten vorst van Gowa, een der rijksgrooten van Gowa en hoofd van Bontoala, was door zijne vrouw verwant niet alleen aan den vorst van Sidenring, doch ook aan de Wadjosche hoofden. Ik meende in hem iemand te zien, die door zijn flink karakter in staat zou zijn aan de wanorde en de onophoudelijke onrust in dat rijk een einde te maken, en wist de kiesheeren over te halen hem tot Aroem-Matowa (hoofdrorst) van Wadjo te doen benoemen. Als Gowasch prins bleef hij echter in Gowa in dezelfde ondergeschikte verhouding tot den vorst staan als de andere palili (vasallen) en had als hoofd van Batoala niets op deze voor.

Van Hoëvell. 
zich uitdrukt, doch list en bedrog waren noodig geweest om dat fiere volk, tegen 't welk de Gowareezen niet opgewassen waren, te onderwerpen. De Badjengers vormden een krijgshaftig volk en nog heden ten dage gaat die roep van hen uit. In den oorlog streden zij immer vooraan. Om echter te begrijpen, waarom zij in de laatste expeditie weigerden aan de zijde van den vorst van Gowa tegen het Gouvernement te strijden, en het zelfs zóóver kwam, dat de vorst, toen hij in October 1905 de vlucht naar Limboeng nam, in de hoop de Toe Badjeng tot deelneming aan den krijg te kunnen overhalen, den Batang bauowa van Limboeng, bij diens halsstarrige weigering daartoe, doodschoot, moeten we kennisnemen van de legende der Toe Badjeng.

Er bestaan, zooals men weet, onder de Makassaren verscheidene van die legenden en verhalen en veel diarvan is door de waardevolle studiën van $D^{r}$. B. F. Matthes aan de vergetelheid outrukt. Ongetwijfeld hebben ook van het verhaal, dat we thans gaan opteekenen, een of meer handschriften bestaan, doch het is me niet mogen gelukken zulk een geschrift in handen te krijgen. Brand en andere rampen hebben het humue er toe bijgedragen veel te doen verloren gaan, wat voor de kennis van land en volk waarde zou hebben. We moeten ons dus vergenoegeu met te luisteren naar den ouden Daeng Nombong, een der aanzienlijksten onder de Toe Badjeng. Hij zit op een mat voor ons en vertelt op de eigenaardige wijze, waarop Inlanders hetgeen hun bij overlevering bekend is weergeven; daarbij doorgaans een geheugen toonende te bezitten, dat eerbied afdwingt. Wanueer hij an het vertellen is, houdt hij telkens even op, als wachtende op een aanmoediging om door te gaan, die we hem dan ook geven. Men ziet aan hem, dat hij er als 't ware geheel in leeft en met een kinderlijk geloof tracht hij ons ook te overtuigen van de waarheid en de schoonheid van 't geen hij mededeelt, want als afstammeling van het geslacht, dat met het vorstelijk gezag over Badjeng bekleed had moeten zijn, is die geschiedenis hem heilig.

Laat ons thans naar hem luisteren!

De eerste en eenige vorst van Badjeng daalde zeer lang geleden te Tanabangka in het gebied van Bantaeng (Bonthain), waar toen een zekere Baso als vorst regeerde, uit den Hemel neer. ${ }^{1}$ Met

1 Bijna alle vorstengeslachten op Zuid-Celebes hebben een dergelijken legendarisehen, mythischen oorsprong nit den Hemel.

v. $\mathrm{H}$ 
hem daalden zes broeders eu ook zijne gemalin Sitti daeng Nisanga neder, zoomede hunne woning. De plaats waar zij op de aarde belandden was gelegen in de nabijheid van den akker van den ouden Salinre. Toen deze op een gegeven oogenblik zag, dat hij buren had gekregen, begaf hij zich naar Bantneng en deelde zijnen Heer mede, dat er zich menschen dicht bij zijn bouwland waren komen vestigen, daaraan tevens toevoegende dat hun herkomst hem onbekend was. De vorst beval hem daarop te gaan onderzoeken, waar die lieden vaudaan waren gekomen en hen aan te zeggen voor hem te verschijnen. Toen Salinre aan deze opdracht voldeed, antwoordde de uit den hemel neergedaalde (Toemanoeroeng) "O Soero, zelf ik weet mijn oorsprong niet, zoomin als ik u de wijze kan zeggen, waarop ik hier gekomen ben, maar ga tot uwen vorst terug en zeg hem, dat als hij mij wenscht te spreken, hij dan tot mij moet komen, daar ik niet tot hem kan gaan, omdat ik doodarm ben (antama tama na boekoe, assoeloe soeloe na boekoeleng, lett. de beenderen gaan binnenwarts en de huid naar buiteu, m.a.w. vleesch is er niet!) Salinre bracht deze woorden aan zijnen vorst over, waarop deze zich gereed maakte om zich vaar de woning van den nieuw aangekomene te begeven. Daar gekomen vroeg hij hem: "Waar komt ge vandaan en met welk doel zijt ge hier gekomen?" waarop de Toemanoeroeng wederom tot bescheid gaf, dat hij zelf niet wist van waar hij kwam. $\mathrm{Nu}$ was het den vorst vań Bautaeng duidelijk, dat hij voor een uit den hemel gedaalde stond en hij sprak ootmoedig, "Heer, als ge hier wilt wonen, zeg het slechts, opdat ik u land geve tot woonplaats". Doch het antwoord luidde, "dat kan ik nu nog niet beslissen, maar als het me hier goed bevalt, blijf ik, anders ga ik elders een woonplaats zoeken." De vorst van Baentaeng leidde nu den Toemanoeroeng rond door zijn land, maar hoeveel streken hem ook getoond werden, nergens vond deze een betere plaats dan die waar hij was neergedaald. Daarom vroeg hij den naam van die streek, waarop de vorst van Bantaeng hem mede. deelde, dat de namen der omliggende landen waren Mamampang, Boengaia, Salo en Tjenrana. Met zijue broeders bewoonde de Toemanoeroeng daarua de dus genoemde streken gedurende eenigen tijd. Echter voldeed die plaats hen al spoedig niet, waarop zij vandaar heengingen en waarna tot op den huidigen dag de genoemde plaatsen ougelukslanden zijn.

Op zijn tochten kwam de Toemanoeroeng eindelijk te Badjeng, gelegen even benoorden de kampong Ballo in 't voormalige regent- 
schap Polombangkeng. Badjeng werd door den Toemanoeroeng tot verblijfplaats verkozen, maar de broeders zetten hun onderzoekingstocht voort, ten einde ieder een eigen land te zoeken. Zoo vestigden zij zich respectievelijk te Katîngang, Pôwang, Tîndang, Sappâia, Barâsa en Kalîmporo, in welke gebieden zij allen onder den titel van Karaeng lowe den scepter $\mathrm{zwaaiden}$ (Karaeng $=$ Heer, vorst; lowe $=$ groot).

De Toemanoeroeng, die nu met zijne vrouw en een'vertrouweling, zekeren Panai, te Badjeng bleef wonen, werd eenstemmig door de Badjengers als Heer erkend, waarom hij van dien tijd af Karaeng lowe ri Badjeng werd genoemd. Zijn nieuw volk bouwde voor hem een echt vorstelijke woning met zeven vakken. Toen Karaeng lowe ri Badjeng daar eenigen tijd gewoond had, verblijdde zijne vrouw hem met de geboorte van een dochtertje, hetwelk zij I Naîma noemden. Hare schoonheid was zouder weerga en als de glans der volle maan.

Op zekeren dag, toen Panai wederom naar buiten ging om de karbouwen van zijn' heer te hoeden, zooals hij gewoonlijk deed, verbrandde hij het hoog opgeschoten riet, om de gelegenheid tot grazen voor zijne dieren te verbeteren. Tot zijne verwondering echter was er één riẹt, dat de vlammen weerstond en ongeschonden bleek te zijn, toen al het overige tot asch geworden was. Hij ging er heen en zag tegen dat riet een zwart hout, twee armlengten lang, welk stuk hout eeu blaasroer bleek te zijn. Ook vond hij er een driekantig pijltje bij van een elleboogslengte. Dat instrument maakte Panai zich ten nutte om er mee op jacht te gaan en als hij er mede schoot was zijn schot zeker en gewis en de pijl viel, na getroffen te hebben, niet op den grond, maar keerde in het blaasroer weer. Gebeurde het een enkele keer dat de pijl naar de aarde daalde, dan was het alleen om een slang of een kikvorsch te treffen, doch ook daarua keerde hij terug. Iederen middag, als hij huiswaarts keerde, bracht Panai een zware vracht vogels tot zijn' heer.

Deze, zich hierover verwonderende, vroeg op een goeden dag aan Panai, "O, Panai, hoe legt ge het toch aan, om de vogels, die ge iederen dag thuis brengt, te vangen?" Panai antwoordde: "ik doe dat niet anders dan met het blaasroer, dat ik vond bij het riet." Daarop nam de vorst het blaasroer en blies er een pijl mee af in de lucht. Die pijl daalde neer op een plaats aan een rechte rivier om daarna terug te keeren tot het blaasroer. De plaats waar die pijl neerkwam werd daarop Ana badjeng genoemd en is gelegen 
in de omgeving van het tegenwoordige Pappa. Die plaats is de bakermat der vorsten - later regenten - van Polombangkeng;, waarom dezen door de bevolking steeds Karaeng Ana badjeng genoemd werden.

Karaeng lowe ri Badjeng noemde het blaasroer nu I Boele; tot belooning werd aan Panai de adelijke titel daeng gegeven en hij voortaan Panai daeng Irate geheeten, onder welken naam hij tot vorst - de eerste - van Galesong werd verheven.

I Naîma groeide op tot een beeldschoone jonkvrouw. Haar naam werd overal bekend en zoo gebeurde het dat de vorst van Gowa Toe mapârisi kalônna, hare schoonheid vernemende, haar tot vrouw begeerde. Daarom belastte hij zijnen soero I Karedjôeroe met de overbrenging van het huwelijksaanzoek. Het antwoord van Karaeng lowe ri Badjeng luidde: "O Soero, keer tot uwen vorst weer en zeg hem, dat ik het aanzoek niet kan aannemen, want dat Gowa en Badjeng niet kuunen samengaan. Gowa zal niet tot Badjeng en dit niet tot Gowa gaan!" Karedjôeroe bracht dit den vorst van Gowa over, waarop deze hem opdroeg zich wederom naar Badjeng te begeven, om den vorst aldaar te verzoeken om, ook al sloeg hij het huwelijksaanzoek af, een feest te geven ter eere van zijne dochter, daar de vorst van Gowa haar dan hoopte te zullen ontmoeten. Dit verzoek werd ingewilligd en de, soero bracht het gunstig antwoord over, zijnen heer mededeelende dat over eenige dagen alles gereed zou ziju.

Karaeng lowe ri Badjeng liet karbouwen slachten, vele in aantal, en onthaalde zijn volk dag en nacht en zond daarvan mededeeling aan den vorst van Gowa. Deze maakte zich daarna op naar Badjeng en nam gansch ziju leger mede. Te Badjeng aangekomen; zag hij het volk verzameld op het feest, maar hij liet den vorst weten, dat zijne bedoeling niet aldus was geweesi, doch met het feest bedoeld was het schermspel met de lans. Het antwoord luidde, "Als dat zoo is, wacht dan slechts eenigen tijd, opdat ik mij gereed kan maken, want zóó heb ik u niet opgewacht, doch slechts met vriendschappelijke gevoelens". Toen de overeengekomen wachttijd om was rukte de vorst van Gowa tegen Badjeng op. Karaeng lowe ri Badjeng nam daarop I Boele en viel uit tegen de Gowareezen. Zijue voorvechters I Banghâsi tjadi tjadi en Tanrâssang bodo bodo gingen vooruit en vele Badjengers volgden hem. De vijand werd dan ook verslagen, daar hij niet was opgewassen tegen de zekerheid, waarmede I Boele trof en den weergaloozen moed, waarmede de 
beide voorvechters vochten. Geheel uiteengeslagen vluchtten de Gowareezen naar hun land terug.

Een jaar daarna werd Badjeng wederom door Gowa aangevallen, maar nu werden de Gowareezen tot Bontonompo teruggeslagen, alwaar een ontelbaar aantal hunuer sneuvelde. De vorst van Gowa liet al die lijken — te veel om behoorlijk te begraven - op een plek in het bosch beoosten Bontonompo verzamelen en met aarde bedekken: waarom de heuvels aldaar nog heden ten dage Balâboeroe (= hoop, stapel) heeten.

Het volgende jaar deden de Gowareezen een derde poging om Badjeng ten onder te brengen, maar wederom werden zij verslagen, totdat hun voorvechter Kare Kolo ri Sero door de voorvechters van Badjeng gevangen genomen werd. Hem vervolgende bereikten Bangkâsi tjadi tjadi en Tanrâssang bodo bodo hem pas te Pekanglâboe, alwaar zij hem dermate troffen, dat zijn hoofd in de batoe nâpara (gladde steen onder 't water) drong. Daarna keerden de beide Badjengers naar hun land en Kare Kolo ri Sero, de verslagene, naar het zijne terug.

De Gowareezen gaven echter den moed niet op en nauwelijks was er wederom een jaar verstreken of zij hadden zich alweer gereed gemaakt om Badjeng aan te tasten. De voorvechters ontmoetten elkaar nogmaals en dreigend stonden zij tegenover elkaar, pochende op hun onkwetsbaarheid. Tanrassang bodo bodo had een koelâoe alo 1 en niemand, zoo sprak hij, kon die kracht weerstaan. Bangkâsi tjadi tjadi had een koelâoe koera en ook tegen die kracht vermocht niemand iets te doen. Kare Kolo ri Sero toonde daarop zijn koelâoe ladja, die hem, zooals hij dreigend verklaarde, de overwinning verzekerde. Zijn tegenstanders echter zeiden hem honend, dat zijn koelâoe geen waarde had, want dat deze kon gespleten worden. Kare Kole ri Sero, willende toonen dat dit onwaar was, gaf toen op zijn koelâoe een harden slag, waarop deze tot zijn grooten schrik werkelijk open sprong en niets dan paardendrek inhield. Geen wonder

1 Volgens het volksgeloof vindt men in vele dieren en vruchten z.g.n. koelâoe's - Koelaoe is de Makassaarsche naam voor bezoarsteenen, moestika, versteeningen, die in verschillende vruchten en dieren gevonden worden en waaraan de inlander eene bijgeloovige kracht toekent, vooral om onkwetsbaar te maken. V. H. - ; steentjes die zoo hard zijn, dat men ze met geen mogelijkheid zou kunnen splijten. Daaraan herkent men dan ook een koelâoe. De koelâoe alo is de koelâoe van een jaarvogel, de koelâoe koera, die van een schildpad en de koelâoe ladja, die van een ladja, d. i. een plant, waarvan de wortels geneeskundige kracht hebben. 
dus, dat hij in den strijd, die volgde, het onderspit delfde. Hij werd achtervolgd tot in een bosch beoosten Bonto Lângbasa en daar sloegen Badjeng's voorvechters hem 't hoofd af, vandaar dat dit bosch nog heden ten dage Romang polong heet (Romang $=$ bosch, polong = breken).

Nogmaals waagden de Gowareezen het een jaar later tegen Badjeng op te rukken. Bij de rivier bij Bilônga gekomen, was de oever aan den Badjengschen kant zóó steil, dat het leger de rivier niet kon oversteken. De Gowareezen riepeu, "Daarom kunnen wij uw land niet bemachtigen, omdat de oevers der rivier te steil zijn." Dit lieteu de Badjengers zich niet zeggen en zeker van de overwiuning, groeven zij den oostelijken oever zoo ver af, dat het Gowasche leger gemakkelijk hun land kom binnen dringen. $\mathrm{Nu}$ nog is op die plaats de oostelijke oever zacht glooiend, daar deze aldus door de Badjengers werd geëffend. Het volk van Gowa stak nu de rivier over, doch de Badjengers vielen hen aan en dreven het vijandelijke leger als een kudde dieren voor zich uit (angêmba), waarom die plek nog heden ten dage Pangembâng wordt geuoemd. Zij joegen de Gowareezen voort tot midden. van 't veld, waar zij hen geheel in de pan hakten. De lijken lagen uitgestrekt op den grond (oêndjoeroe), waarom die plaats thans nog Pangoendjoêrang heet. Toen de strijd geëindigd was, richtten de Badjengers een feestmaal aan en dekten (tongko) de spijzen met etensdeksels. De plaats waar dit geschiedde wordt nu nog Manongkôki (van tongko) genoemd.

Moedeloos en terneer geslagen keerde de vorst van Gowa naar zijn land terug en daar vernam hij, dat de Badjeugers onoverwinnelijk waren, omdat zij eeu blaasroer, dat met zekerheid trof en doodde, als gaoekang ' hadden, welk blaasroer I Boele heette. Toen zeide de beroemde waarzegger Boto Lempangang tot den vorst, dat hij naar Badjeng zou gaan om, zooals hij het uitdrukte, het hoofd en de beenen aldaar vau den romp te scheiden en den buik des lands open te rijten, om daarna I Boele weg te nemen en hem aan den vorst van Gowa te geven. Verheugd over die woorden liet de vorst

1 Gaoekang (gaoe beteekent doen) is de nam van het voornaamste rijksornament, waarvan het bezit noodzakelijk is om als vorst over het land te kunnen regeeren. Zie hieromtrent „De feitelijke toestand in het Gouvernementsgebied van Celebes en onderhoorigheden" van P. J. Kooreman in de Indische Gids 1883.

(Als ethnographische bizonderheid is uit deze legende af te leiden, dat ook op Zuid-Celebes 't blaasroer als oorlogswapen heeft dienst gedaan. v. H.) 
hem gaan. Aan de poort van het erf van Karaeng lowi ri Badjeng gekomen, zeide hij tot den poortwachter I Lawanna, "Ik ben Boto Lempangang en kom den vorst van Badjeng bezoeken, meld mij dus an". Zoo deed de wachter, die met de boodschap terugkwam, dat de bezoeker welkom zou zijn. Daarop ging Boto Lempangang de vorstelijke woning binnen en verscheen voor Karaeng lowo ri Badjeng. Op de vraag met welk doel hij kwam, antwoordde Bote Lempangang, "O Heer, ik kom slechts hier om mijn levensonderhoud te zoeken, want de vorst van Gowa vervolgt mij, daar hij mij beschuldigt van zijne dochter te hebben willen verleiden, zoodat hij mij, als ik hem in handen val, zal dooden." Hij kreeg daarop vergunning in Badjeng te blijven, opdat hij veilig zou zijn, want in Badjeng zou de vorst van Gowa hem zeker ongemoeid laten. Boto Lempangang bleef bij Karaeng lowe ri Badjeng wonen, maar wat hij ook verzon om I Boele te bemachtigen, hij slaagde niet.

Langzamerhaud wist hij zich in 's vorsten gunst dusdanig in te dringen, dat al wat hij zeide immer een gewillig oor bij dezen vond. Hij raadde nu aan een gracht door het land te graven van het oosten des lands door 't midden naar 't zuiden, den vorst verzekerende, dat daardoor het land in kracht zou toenemen en iederen vijand dan belet zou kunnen worden 't land binnen te dringen Vertrouwend volgde Karaeng lowe ri Badjeng dien raad op. Vandaar dat nu nog te Badjeng de eene zijde van het land hoog en de andere laag is. Dit gedaan zijnde verliet Boto Lempangang het land van Badjeng en keerde tot Gowa terug tot welks vorst hij zeide: "Ik heb Badjeng het hoofd en de beenen van den romp gescheiden en de buik opengesneden." De vorst van Gowa wantrouwde de zaak echter, omdat Boto Lempangang I Boele niet tot hem gebracht had. Daarom was hij zeer bekommerd.

Dit vernam Panai daeng Irate, eertijds volgeling van Karaeng lowe ri Badjeng en door dezen - zooals we zagen - verheven tot vorst van Galesong. Hij begaf zich naar Gowa en deelde den vorst mee, dat hij I Boele wel door een list zou kunnen bemachtigen, daar I Boele oorspronkelijk hem behoord had. Hij sprak tot den vorst: "Volg slechts mijn raad op en doe Heer, alsof ge zeer vergramd op mij zijt en daarom tegen Galesong wilt optrekken om mij te straffen. Ik zal dan vluchten en de hulp vau Badjeng inroepen. Het moet echter niet tot een strijd komen, dus als ik met Karaeng lowe te Galesong aankom, moeten wij U daar niet meer 
vinden". Zoo trokken de Gowareezen op zekeren dag naar Galesong. Panai vluchtte naar Badjeng en Karaeng lowe ri Bandjeng was onmiddellijk bereid zijn' ouden getrouwe bij te staan. Te Galesong aangekomen vonden zij de Gowareezen niet meer, daar dezen, zooals Panai gezegd had, reeds teruggegaan waren. Daarom bleef uu Panai wederom te Galesong en de vorst van Badjeng keerde huiswaarts in den waan, dat Gowa en Galesong vijanden van elkaar waren. Kort daarop noodigde Panai nu den vorst van Badjeng uit om te Talamangape samen te komen, ten einde daar een feestmaal aan te richten. Te Talamangape was overvloed van palıwijn en Panai zou heerlijke visch van Galesong mee ten maaltijd brengen. Vooraf liet hị echter een groote hoeveelheid droog hout en droge bladeren verzamelen en die op 't veld opstapelen zoo hoog als zijn eigen huis, terwijl hij zijn volk opdroeg, dat alles in brand te steken, zoodra 't feest in vollen gang zou zijn.

$\mathrm{Nu}$ steeg hij te paard en begaf zich naar Talamangape, waar weldra den feestdisch alle eer werd aangedaan. Tegen den avond staken de Galesongers nu den stapel hout en bladeren in brand en weldra sloegen de vlammen hoog het luchtruim in, zoodat de vuurgloed duidelifk van Talamangape uit was te zien. Toen klaggde Panai daeng Irate Karaeng Galesong: "O Heer, zie toch, daar verbranden de Gowareezen mijn land". En Karaeng lowe ri Badjeng beloofde hem te zullen bijstaan, maar toen sprak Panai plotseling: "Geef mij I Boele, hij alleen is in staat den vijand te verjagen". Badjeng's vorst stemde toe, maar sprak den volgenden duren eed: "Als ge mij bedriegt en ge brengt me I Boele niet terug, zoo ga het $\mathrm{u}$ eeuwig slecht, zoo moget ge blijven zonder nageslacht als een boom zonder takken en loten, zoo moge vuilnis $U$ ten voedsel strekken en uw kleederen vol gaten zijn als de netten, warmee men vischt; moge dan de nok van het huis, dat ge bewoont zich naar beneden keeren en de stijlen naar boven zijn gericht", Karaeng Galesong echter liet zich door dien vloek niet afschrikken, nam I Boele en steeg te paard. Hij rende naar Gowa in dolle vaart. In zeker bosch gekomen, brak de toom en hij steeg af om die te makeu (pare). Een eind verder rustte hij en stak een strootje op (kado pepe) en wederom wat verder sueed hij een takje in het woud in den vorm van een hertehoorn (tangke djonga) om daarvan een zweep te maken voor zijn paard.

Te Gowa aangekomen schonk hij I Boele aan den vorst, die daarover zeer verheugd was en Panai vroeg, waarmede hij hem 
beloonen kon. Panai echter vroeg slechts de vriendschap van den vorst. Hij verhaalde hem van zijn tocht en toen schonk de vorst van Gowa hem de drie bosschen, waar hij getoefd had en thans nog zijn die bosschen bekend als die van Pare pare, Bonto Kadoepepe en Tangke djonga en behooren nog tot de ornamenten van den vorst - thans regent - van Galesoug.

Hier hield de verteller even op en met een blik, die geen twijfel liet omtrent den ernst, die hem bezielde, voegde hij er naïef aan toe: "En de eed is geheel nitgekomen, want de tegenwoordige oude Regent sterft kinderloos en het geheele geslacht is door ongeluk getroffen. Is niet de regent van Labakkang — ook een na-familielid van 't Galesongsche regenten-geslacht - onlangs van Celebes verbannen?"

Daarop hervatte hij het verhaal en sprak: Karaeng lowe ri Badjeng, dit schelmstuk vernemende, riep de hoofden van Badjeng te zamen en wel Kadere, Glarrang Badjeng, I Lawanni, Glarrang Ballo en Boerane, Glarrang Mataällo en hij zeide hen : "Gaat thans naar Gowa, want I Boele moet ge volgen, ik zelf zal heengaan." Hij gaf den Glarrang Badjeng zijn buikband, geuaamd Djoelle djoellêia en zijn lans genaamd I Tamanjâla en zeide "deze voorwerpen zullen mij zelven bij u vervangen".

Deze woorden geuit hebbende ging hij heen met zijn vrouw en zijne dochter, terwijl Tanrâssang bode bodo en Bangkâsi tjadi tjadi volgden. Sinds zijn gij verdwenen en nimmer werd iets omirent hun wedervaren of hun verblijfplaats bekend, terwijl ook niemand weet, hoe zij verdwenen zijn. Aldus ging het ook met de zooeven genoemde zes broeders van Karaeng lowe ri Badjeng. Zij allen verdwenen van deze wereld.

De Badjengers, geen vorst meer hebbende, verspreiddeu zich. Er waren er die zuidwaarts gingen naar Toeratêia, er zijn er die noordwaarts gingen naar Maros, er gingen er eenigen naar audere plaatsen. Maar de drie glarrangs vestigden zich met 40 zielen in het gebied van Gowa en wel te Limboeng. De Glarrang van Badjeng bleef in 't oosten, Glarrang Ballo in het midden en Glarrang Mataällo in 't noorden wonen. De beide laatste glarrangs gaven aan hunne nieuwe woonplaatsen den naam van hun land. De eerste noemde slechts een bosch, te Limboeng gelegen, naar zijn voormalig gebied. De 4.0 gezinnen vermenigvuldigden zich, en hunne nakomelingen vormen thans de bewoners der 3 genoemde plaatsen.

De grijsaard zweeg. Het vertellen had hem ingespannen, en vermoeid nam hij afscheid. 
Voorts gewaagt de geschiedenis van verscheidene oorlogen tusschen Gowa en Badjeng, terwijl de Toe Badjeng nimmer tot de getrouwe volgelingen vau Gowa hebben behoord. Zij zijn met Gowa, zooals de Makassaar dat uitdrukt als djêne nipalêioki mînja d.w.z. water vermengd met olie; een innige vermenging is onmogelijk.

Zooals we reeds zagen, hebben zij in den strijd tusschen het Gouvernement en Gowa's vorst de wapeus niet opgevat om dezen ter zijde te staan. Zij hebben zijn val met onverschilligheid gadegeslagen en zijn thans rustige onderdanen van het NederlandschIndische Gouvernement.

Takalar, Juni 1907, 